\title{
Should we wait until severe pulmonary hypertension develops? Efficacy of percutaneous mitral balloon valvuloplasty in patients with severe pulmonary hypertension: A subgroup analysis of our experience
}

\author{
Hakan Ozkan ${ }^{1}$, Tahsin Bozat ${ }^{2}$, Selma Kenar Tiryakioglu ${ }^{3}$, Hasan Ari $^{4}$ \\ ${ }^{1}$ Department of Cardiology, Bahcesehir University Faculty of Medicine, Istanbul, Turkey \\ ${ }^{2}$ Department of Cardiology, Medicalpark Hospital, Bursa, Turkey \\ ${ }^{3}$ Department of Cardiology, Bursa State Hospital, Bursa, Turkey \\ ${ }^{4}$ Department of Cardiology, Bursa Yuksek Ihtisas Egitim ve Arastirma Hastanesi, Bursa, Turkey
}

\section{Abstract}

Background: The primary goal of this study is to evaluate the immediate and long-term effects of percutaneous mitral balloon valvuloplasty (PBMV) on patients with rheumatic mitral stenosis (MS) complicated with severe pulmonary hypertension (PH).

Methods: The study population consisted of 85 patients with MS complicated with severe $\mathrm{PH}$ (systolic pulmonary pressure $>75 \mathrm{~mm} \mathrm{Hg}$ ). PBMV was performed with Inoue balloon technique. Clinical and echocardiographic follow-up was scheduled at 6 months and 1 year and yearly thereafter.

Results: Mitral valve area (MVA) was increased (pre-PBMV MVA was $1.03 \pm 0.21 \mathrm{~cm}^{2}$, post-PBMV MVA $\left.1.89 \pm 0.34 \mathrm{~cm}^{2}, p<0.001\right)$ significantly. The mean and the maximum transmitral pressure gradient significantly decreased (pre-PBMV mean transmitral gradient was $18.47 \pm 6.59 \mathrm{~mm} \mathrm{Hg}$, post-PBMV $6.84 \pm 3.84 \mathrm{~mm} \mathrm{Hg}$, $p<0.001$, pre-PBMV maximum transmitral pressure gradient was $27.6 \pm 8.38 \mathrm{~mm} \mathrm{Hg}$, post-PBMV $12.68 \pm 4.74 \mathrm{~mm} \mathrm{Hg}$, $p<0.001)$. Systolic pulmonary artery pressure $(S P A P)$ significantly decreased (pre-PBMV $89.9 \pm 23.38 \mathrm{~mm} \mathrm{Hg}$, post-PBMV $54.5 \pm 14.6 \mathrm{~mm} \mathrm{Hg}$, $p<0.001$ ). Two patients underwent surgery due to rupture of anterior mitral leaflet. There was no peri-procedural mortality. The procedure time was $29.12 \pm 11.37$ min. Follow-up duration was $108.2 \pm 31.4$ months. One patient died due to heart failure. One patient underwent re-PBMV and 7 patients mitral valve replacement. At the last follow-up, MVA still remained high $\left(1.52 \pm 0.34 \mathrm{~cm}^{2}\right)$ and mean transmitral pressure gradient was low $(9.2 \pm 5.7 \mathrm{~mm} \mathrm{Hg})$. SPAP was $56.5 \pm 20.8 \mathrm{~mm} \mathrm{Hg}$ which was the same as after PBMV.

Conclusions: $P B M V$ in patients with $M S$ with severe $P H$ is an effective therapy with low procedure time. However, it is recommended to perform PBMV before developing severe PH. (Cardiol J 2016; 23, 2: 184-188)

Key words: mitral valve, pulmonary hypertension, balloon valvuloplasty, long-term results, mitral stenosis

Address for correspondence: Hakan Ozkan, MD, Çırağan Caddesi Osmanpaşa Mektebi Sokak No: 4-6, 34353 Beşiktaş, İstanbul, Türkiye, tel:+90 224 2706145, fax: +90224 2235571, e-mail: doctorhakan@hotmail.com 


\section{Introduction}

Percutaneous mitral balloon valvuloplasty (PBMV) is an effective therapy in patients with symptomatic mitral stenosis (MS) [1-3]. In addition, PBMV is the best choice for isolated MS with favorable morphology [4]. However, long-term effects of PBMV in high-risk MS patients including severe pulmonary hypertension $(\mathrm{PH})$, low ejection fraction, and severe tricuspid regurgitation have infrequently been evaluated. Maoqin et al. [5] followed up patients with MS complicated mild to severe PH for 24 months. The study has demonstrated that PBMV can improve immediate and long-term outcomes of patients with MS complicated by severe PH despite inferior hemodynamic results [5]. The primary goal of this study was to evaluate the immediate and long-term (at least 5 years) results of PBMV in MS patients with severe $\mathrm{PH}$.

\section{Methods}

From 1994 to 2010, a total 85 out of 435 patients were included in the study. The criteria for inclusion in the study were defined as MS (mitral valve area $[\mathrm{MVA}] \leq 1.2 \mathrm{~cm}^{2}$ ) with symptoms of New York Heart Association (NYHA) functional class II to IV complicated by systolic pulmonary artery pressure (SPAP) above $75 \mathrm{~mm} \mathrm{Hg}$. Patients with mitral regurgitation $(\mathrm{MR}) \geq$ grade 3 , moderate to severe aortic disease (aortic valve area $<1.5 \mathrm{~cm}^{2}$ and maximum aortic velocity $>3.0 \mathrm{~m} / \mathrm{s}$, or moderate to severe aortic regurgitation according to echocardiographic assessment including pulsed wave (PW) Doppler mapping technique, jet height/left ventricular outflow tract [LVOT] height and jet area/LVOT area), known coronary artery disease (coronary artery stenosis $>50 \%$ ), or left atrial thrombus were excluded from the study.

Clinical statuses of all patients were determined by NYHA classification. All patients underwent transthoracic (TTE) and transesophageal (TEE) echocardiographic examination before PBMV. TTE control was performed to evaluate MVA and other parameters $24 \mathrm{~h}$ after PBMV. TTE evaluation included Wilkins scoring [6], MVA calculation by both planimetric method (MVA measurement by tracing in the short axis view [7]) and pressure half-time method [8], and MR estimation (graded as none, mild, moderate or severe by colorDoppler semiquantitative method) [9]. Clinical and echocardiographic follow-up was scheduled at 6 months and 1 year and yearly thereafter. Follow-up
Table 1. Baseline characteristics.

\begin{tabular}{lc}
\hline Parameters & Study population $(\mathbf{n}=85)$ \\
\hline Age [years] & $34.8 \pm 10$ \\
Gender (female) & $73(85.8 \%)$ \\
Wilkins Score & $7.89 \pm 2$ \\
Ejection fraction [\%] & $64 \pm 3.16$ \\
Sinus rhythm [\%] & $67(78.8 \%)$ \\
NYHA class II & $8(9.4 \%)$ \\
NYHA class III & $42(49.4 \%)$ \\
NYHA class IV & $35(41.1 \%)$ \\
Balloon size & $26.9 \pm 1.07$ \\
Procedure time [min] & $29.12 \pm 11.37$ \\
\hline
\end{tabular}

NYHA - New York Heart Association

period was planned at least 4 years. PBMV was performed with the Inoue balloon catheter (Toray International America Inc.). Probe patency was searched and used in patients with previous patent foramen ovale as described in the previous study [10]. Ideal balloon size was calculated by the height based formula: Balloon size $(\mathrm{mm})=$ (height of patient in $\mathrm{cm} / 10)+10$.

PBMV was performed by stepwise or single inflation method defined earlier [11]. Hemodynamic measurements were repeated after PBMV. Success of PBMV was defined as post-PBMV MVA $>1.5 \mathrm{~cm}^{2}$ or an increase $>50 \%$ relative to the baseline value with no severe MR.

The study was approved by the local ethical committee and all patients gave their informed consent.

\section{Statistical analysis}

Statistical analysis was performed using SPSS 10 program. Data are presented as mean \pm standard deviation. A value of $\mathrm{p}<0.05$ was considered significant. Two-paired Student's t test was used for continuous variables and $\chi^{2}$ tests for categorical variables.

\section{Results}

Most of the patients were female (73, 85.8\%) with a $34.8 \pm 10$ years mean age. Out of all patients, $78.8 \%$ with sinus rhythm. Acute procedural success rate was $100 \%$ in 85 patients. Mean procedure time (from puncture of the femoral vein to successful PBMV) was $29.12 \pm 11.37 \mathrm{~min}$. More than $90 \%$ of the study population had NYHA III-IV functional capacity. Baseline characteristics are displayed in Table 1. 
Table 2. Hemodynamic measurements before and after percutaneous balloon mitral valvuloplasty (PBMV).

\begin{tabular}{lccc}
\hline & Pre-PBMV & Post-PBMV & P \\
\hline Systolic pulmonary artery pressure $[\mathrm{mm} \mathrm{Hg}]$ & $93.27 \pm 18.35$ & $57.09 \pm 18.82$ & $<0.001$ \\
Mean pulmonary artery pressure $[\mathrm{mm} \mathrm{Hg}]$ & $57.29 \pm 11.46$ & $33.72 \pm 12.94$ & $<0.001$ \\
Mean mitral gradient $[\mathrm{mm} \mathrm{Hg}]$ & $23.34 \pm 5$ & $4.42 \pm 3.21$ & $<0.001$ \\
Pulmonary capillary wedge pressure $[\mathrm{mm} \mathrm{Hg}]$ & $32.43 \pm 6.76$ & $13.81 \pm 7.53$ & $<0.001$ \\
\hline
\end{tabular}

Table 3. Echocardiographic measurements before and after percutaneous balloon mitral valvuloplasty (PBMV).

\begin{tabular}{lccc}
\hline & Pre-PBMV & Post-PBMV & P \\
\hline Ejection fraction [\%] & $64 \pm 3.16$ & $64.8 \pm 4.22$ & NS \\
Left atrium [cm] & $4.73 \pm 0.52$ & $4.47 \pm 0.5$ & $<0.001$ \\
SPAP [mm Hg] & $89.94 \pm 23.28$ & $54.58 \pm 14.67$ & $<0.001$ \\
MVA (planimetric method) [cm $\left.{ }^{2}\right]$ & $1.03 \pm 0.21$ & $1.89 \pm 0.34$ & $<0.001$ \\
MVA (PHT method) [cm $\left.{ }^{2}\right]$ & $1.04 \pm 0.23$ & $1.91 \pm 0.33$ & $<0.001$ \\
Mean TG [mm Hg] & $18.47 \pm 6.59$ & $6.84 \pm 3.84$ & $<0.001$ \\
Maximum TG [mm Hg] & $27.6 \pm 8.38$ & $12.68 \pm 4.74$ & $<0.001$ \\
\hline
\end{tabular}

MVA — mitral valve area; NS — non-significant; SPAP — systolic pulmonary artery pressure; PHT — pressure half-time; TG — transmitral gradient

Table 4. Echocardiographic follow-up.

\begin{tabular}{lccccc}
\hline & Pre-PBMV & Post-PBMV & First year & Second year & Last follow-up \\
\hline $\begin{array}{l}\text { MVA (planimetric method) } \\
{\left[\mathrm{cm}^{2}\right]}\end{array}$ & $1.03 \pm 0.21$ & $1.89 \pm 0.34$ & $1.81 \pm 0.3$ & $1.79 \pm 0.3$ & $1.53 \pm 0.37$ \\
$\begin{array}{l}\text { Mean transmitral gradient } \\
\text { [mm Hg] }\end{array}$ & $18.47 \pm 6.59$ & $6.84 \pm 3.84$ & $7.0 \pm 3.1$ & $8.4 \pm 4.3$ & $9.2 \pm 5.7$ \\
SPAP [mm Hg] & $80.94 \pm 23.28$ & $54.58 \pm 14.67$ & $51.9 \pm 17$ & $53.2 \pm 20.3$ & $55.7 \pm 20.6$ \\
Left atrium [cm] & $4.73 \pm 0.52$ & $4.47 \pm 0.5$ & $4.31 \pm 0.6$ & $4.39 \pm 0.5$ & $4.45 \pm 0.54$ \\
\hline
\end{tabular}

MVA - mitral valve area; PBMV — percutaneous balloon mitral valvuloplasty; SPAP — systolic pulmonary artery pressure

The mean transmitral pressure gradient, SPAP and mean pulmonary artery pressure (PAP) and pulmonary capillary wedge pressure (PCWP) significantly decreased after PBMV. Details of invasive measurements before and after PBMV is shown in Table 2.

MVA was increased (pre-PBMV MVA was $1.03 \pm 0.21$, post-PBMV MVA $1.89 \pm 0.34 \mathrm{~cm}^{2}$, $\mathrm{p}<0.001)$ significantly. The mean and the maximum transmitral pressure gradient significantly decreased (pre-PBMV mean transmitral gradient was $18.47 \pm 6.59 \mathrm{~mm} \mathrm{Hg}$, post-PBMV $6.84 \pm$ $\pm 3.84 \mathrm{~mm} \mathrm{Hg}, \mathrm{p}<0.001$; pre-PBMV maximum transmitral pressure gradient was $27.6 \pm 8.38 \mathrm{~mm}$ $\mathrm{Hg}$, post-PBMV $12.68 \pm 4.74 \mathrm{~mm} \mathrm{Hg}, \mathrm{p}<0.001)$. SPAP significantly decreased (pre-PBMV $80.9 \pm$ $\pm 23.38 \mathrm{~mm} \mathrm{Hg}$, post-PBMV $54.5 \pm 14.6 \mathrm{~mm} \mathrm{Hg}$, $\mathrm{p}<0.001)$. The echocardiographic data are shown in Table 3 and echocardiographic follow-up in Table 4. Eighty-eight percent of patients were followed at the end of the study. Mitral valve replacement was needed due to severe MR in 2 patients due to rupture of anterior leaflet of mitral valve.

Major adverse cardiac events. Mean followup duration was $108.2 \pm 31.4$ months. Eighty-eight percent of all patients were followed-up successfully. During the follow-up period the events were:

Death. One patient died due to Lutembacher syndrome.

Mitral valve replacement. Seven (8.23\%) patients underwent surgical therapy indicated by: 
MR in 1, combination of progressive aortic valve disease in 3 and restenosis in 3.

Repeat PBMV: One (1.17\%) patient underwent repeated PBMV.

\section{Discussion}

Pulmonary hypertension is a frequent complication of MS. The main mechanism responsible for the development of $\mathrm{PH}$ is passive retrograde transmission of elevated left atrial-pulmonary venous pressure into pulmonary arterial vasculature. Pulmonary venous hypertension induces reactive pulmonary arteriolar vasoconstriction [12].

Previous studies have shown that successful balloon valvotomy decreased the pulmonary systolic pressure and the pulmonary vascular resistance to normal or near-normal values in patients with mild PH [13-16].

ACC/AHA/ESC guidelines recommend PBMV in symptomatic patients with MS and asymptomatic patients with high PAP (at rest $>50 \mathrm{~mm} \mathrm{Hg}$ ) as well. However, there are limited data about the symptomatic patients complicated with $\mathrm{PH}$. This group of patients is usually accompanied by moderate to severe tricuspid insufficiency with impaired functional capacity and may represent delayed for interventional therapy.

Maoquin et al. [5] compared two groups of patients with $\mathrm{PH}>80 \mathrm{~mm} \mathrm{Hg}$ and $<50 \mathrm{~mm} \mathrm{Hg}$ according to PAP. These patients were followed for 24 months. In this study, in the group with severe PAP, PAP decreased from $97.8 \pm 21.5 \mathrm{~mm} \mathrm{Hg}$ to $54.8 \pm 5.8 \mathrm{~mm} \mathrm{Hg}$ after PBMV. Maoquin et al. [5] reported good clinical response despite low hemodynamic results.

In our study, SPAP decreased similarly after PBMV from $89.9 \pm 23.38 \mathrm{~mm} \mathrm{Hg}$ to $54.5 \pm$ $\pm 14.6 \mathrm{~mm} \mathrm{Hg}$. Unlike the previous study, our follow-up period is $108.2 \pm 31.4$ months. During the follow-up period, PAP decreased immediately after the procedure and made a plateau value. At the end of the follow-up period, the PAP remained high when the MVA was $1.52 \pm 0.34 \mathrm{~cm}^{2}$. We calculated the value $55.7 \pm 20.6 \mathrm{~mm} \mathrm{Hg}$ at the end.

Cruz-Gonzales et al. [17] studied the effect of pulmonary vascular resistance (PVR) on outcomes of PBMV in 2013. Two hundred and sixty-three of 926 patients had elevated PVR ( $\geq 4$ Woods unit). The mean PAP in patients with elevated PVR was $49.17 \pm 13.59 \mathrm{~mm} \mathrm{Hg}$ pre-procedure and significantly decreased after PBMV (38.24 $\pm 12.55 \mathrm{~mm}$ $\mathrm{Hg}$ ). They declared that PVR is not an independent predictor of procedural success or long-term results. Selected patients with rheumatic mitral stenosis might benefit from PBMV despite the presence of elevated pre-procedural PVR. In our study, we did not calculate the PVR, however we used PAP. Hemodynamically, pre-PBMV the mean PAP was $57.29 \pm 11.46 \mathrm{~mm} \mathrm{Hg}$ and $33.72 \pm$ $\pm 12.94 \mathrm{~mm} \mathrm{Hg}$ after procedure, respectively. The mean PAP was significantly higher in our study population. When we evaluated the echocardiographic parameters, pre-PBMV SPAP was $89.94 \pm$ $\pm 23.28 \mathrm{~mm} \mathrm{Hg}$ which was significantly decreased after the procedure $(54.58 \pm 14.67 \mathrm{~mm} \mathrm{Hg})$ and remained high at the last follow-up period ( $55.7 \pm$ $\pm 20.6 \mathrm{~mm} \mathrm{Hg}$ ). Our findings showed that high pre-procedural PAP did not affect the procedural success as stated by results by Cruz-Gonzales et al. [17]. However, at the end of the follow-up period, SPAP remained high. These findings suggest that performing PBMV before high PAP may improve functional capacity. Therefore, we think we should not wait until severe PH developed in patients with rheumatic MS for PBMV. However, larger multicenter studies are needed to clarify this hypothesis.

These results confirm that PAP increases during the natural course of mitral stenosis and becomes irreversible after a certain value. Therefore, we suggest that if PBMV is performed before severe $\mathrm{PH}$ develops, it may prevent irreversible changes in the pulmonary vascular bed.

\section{Conclusions}

The present study demonstrated excellent immediate results of PBMV in patients with symptomatic MS complicated by severe $\mathrm{PH}$ with a lower procedure time. Long-term results were comparable with previous studies. However, we recommended performing PBMV before developing severe PH. Further larger multicenter studies are needed for clarifying this hypothesis.

\section{Conflict of interest: None declared}

\section{References}

1. Hrerrmann HC, Wilkins GT, Abascal VM, Weyman AE, Block PC, Palacios IF. Percutaneous balloon mitral valvotomy for patients with mitral stenosis: Analysis of factors influencing early results. J Thorac Cardiovasc Surg, 1988; 96: 33-38.

2. Block PC, Palacios IF, Block EH, Tuzcu EM, Griffin B. Late (twoyear) follow-up after percutaneous balloon mitral valvotomy. Am J Cardiol, 1992; 69: 537-541.

3. Palacios IF, Block PC, Wilkins GT, Weyman AE. Follow-up of patients undergoing percutaneous mitral balloon valvotomy 
analysis of factors determining restenosis. Circulation, 1989; 79: 573-579.

4. Chen CR, Cheng TO; for the Multicenter Study Group, Percutaneous balloon mitral valvuloplasty by the Inoue technique: A multicenter study of 4832 patients in China. Am Heart J, 1995; 129: 1197-1203.

5. Maoqin S, Guoxiang H, Zhiyuan S et al. The clinical and hemodynamic results of mitral balloon valvulaoplasty for patients with mitral stenosis complicated by severe pulmonary hypertension. Eur J Intern Med, 2005; 16: 413-418.

6. Wilkins GT, Weyman AE, Abascal VM, Block PC, Palacios IF. Percutaneous balloon dilation of the mitral valve: An analysis of echocardiographic variables related to outcome and mechanisms of dilation. Br Heart J, 1988; 60: 229-308.

7. Henry WL, Griffith JM, Michaelis LL, McIntosh CL, Morrow AG, Epstein SE. Measurement of mitral orifice area in patients with mitral valve disease by real-time, two-dimensional echocardiography. Circulation, 1975; 51: 827-831.

8. Hatle L, Angelsen B, Tromsdal A. Noninvasive assessment of atrioventricular pressure half-time by Doppler ultrasound. Circulation, 1979; 60: 1096-1104.

9. Helmcke F, Nanda NC, Hsiung MC et al. Color Doppler assessment of mitral regurgitation with orthogonal planes. Circulation, 1987; 75: 175-183.

10. Bozat T, Sarıkamıs C, Koca V, Akkaya V. The feasibility of using patent foramen ovale during mitral balloon valvuloplasty. J Invasive Cardiol, 1998; 10: 545-547.
11. Ozkan H, Bozat T, Ari H, Tiryakioglu SK, Koca MV. Should an inoue balloon larger than suggested by guidelines be used for percutaneous balloon mitral valvuloplasty? J Heart Valve Dis, 2013; 22: 660-664.

12. Wood P. Pulmonary hypertension with special reference to the vasoconstrictive factor. $\mathrm{Br}$ Heart J, 1958; 20: 557-568.

13. Fawzy ME, Hassan W, Stefadouros M, Moursi M, El Shaer F, Chaudhary MA. Prevalance and fate of severe pulmonary hypertension in 559 consecutive patients with rheumatic mitral stenosis undergoing mitral balloon valvotomy. J Heart Valve Dis, 2004; 13: 942-947.

14. Gamra H, Zhang HP, Allen JW, Lou FY, Ruiz CE. Factors determining normalization of pulmonary vascular resistance following successful balloon mitral valvotomy. Am J Cardiol, 1999; 83: 392-395.

15. Otto CM, Davis KB, Reid CL et al. Relation between pulmonary artery pressure and mitral stenosis severity in patients undergoing balloon mitral commissurotomy. Am J Cardiol, 1993; 71 874-878.

16. Riberio PA, Alzaibagh M, Abdullah M. Pulmonary artery pressure and pulmonary vascular resistance before and after mitral balloon valvotomy in 100 patients with severe mitral stenosis. Am Heart J, 1993; 125: 1110-1114.

17. Cruz-Gonzales I, Semigram MJ, Inglessis-Azuaje I et al. Effect of elevated pulmonary vascular resistance on outcomes after percutaneous mitral valvuloplasty. Am J Cardiol, 2013; 112: $580-584$. 